Original Contribution

\title{
MOTIVES FOR SUBCONTRACTING EXTERNAL AUDITORS' WORK TO OTHERS
}

\author{
R. Petkov* \\ Lehman College, City University of New York, USA
}

\begin{abstract}
In this paper, we argue that it could be beneficial for routine external audit work to be subcontracted to other auditors and this could be accomplished without affecting the quality of the external audit. The rationale for such activities could range from economic constraints, such as limited staff to complete the audit engagement to more general, such as lack of specific knowledge for certain accounting/audit areas. As key premise to this argument, we note that before such subcontracting could occur, the initial external auditors must be satisfied with subcontracted external audit activities and they have to ensure they meet the established standards of audit quality in order to render an audit opinion. This would ensure that the other auditors are independent of the client and qualified enough to handle the assigned tasks. These procedures are similar to the ones undertaken by external auditors to evaluate whether they could use the work of the internal auditors.
\end{abstract}

Key words: subcontracting, external audit, secondary auditor

\section{INTRODUCTION}

It is not uncommon for external auditors to delegate certain area or component of the audit engagement to other auditors. Particularly, the initially engaged audit firm could subcontract and therefore delegate certain routine work to outside hired "secondary" auditors. These auditors act as subcontractors to the initially hired firms. In this paper, we argue that such routine work could be beneficial without affecting the quality of the audit. It must be noted that before such subcontracting could occur, the initial auditors have to be satisfied that the subcontracted audit activities meet the established standards of audit quality. They have to also ensure that the other auditors are independent of the client and qualified enough to handle the assigned tasks. These procedures are critical before subcontracting could occur. Otherwise, there is the risk that the audit would not meet its objective of providing a proper opinion on the quality of the financial statements. Therefore, proper care needs to be exercised when subcontracting external auditors to perform certain audit portions. In this paper, we argue that such premise could be achieved by properly executed audit plan for the use of others. Furthermore, in this paper we

\footnotetext{
* Correspondence to: Rossen R. Petkov, City University of New York, Lehman College, USA, E-mail: rossen.petkov@lehman.cuny.edu
}

analyze some of the advantages and disadvantages to engage external "secondary" auditors to perform some of the work. In addition, we discuss and provide examples of some typical audit areas that could be subcontracted.

As a starting point, we note that the objective of subcontracting external auditors is to create the "medium" for the initial auditor to focus on the more technical areas and the subcontractor could focus on routine areas. A reason for subcontracting some portion of the audit to another firm could be due to the audit being large; it could be overwhelming for one team to handle and the time to hire and train new employees could be limited. In such case, it makes sense to hire or subcontract an outside firm to come in and immediately handle the audit. Also, most often the client may have other businesses in foreign countries, and so the primary audit firm might find it beneficial to subcontract a portion of the audit to a foreign audit firm. In this instance, it is necessary for the primary audit firm to supervise and review the work being done by the subcontractor. The PCAOB rule does state that if the audit is subcontracted the primary audit firm that is engaged to do the audit is primary responsible (1-2). This means they will be liable for the work done by the subcontracting audit firm, as they are the audit 
firm that is engaged to do the audit. Therefore, proper care needs to be exercised when selecting and managing/delegating the work of the subcontracted auditor.

\section{ANALYSIS}

By definition, these "other auditors" or subcontractors are technically referred to as "component auditors" (1). Their primary function is to perform audit work on the financial information of the engaged component and provide audit evidence to be used the rendering of audit opinion (1). Per PCAOB, a "component auditor may be part of the group engagement partner's firm, a network firm, or another firm" (1-2). It is important to note that such subcontracting activity could be beneficial to both the initially engaged audit firm and the subcontracted other auditors. The benefit for the delegating firm would be the reduced cost of achieving a quality audit. That is, the engaging audit firm would consider subcontracting some of its services to outsiders if it can achieve reduction in its cost without impact on the audit quality. In order to ensure that such a goal is accomplishable, ideally the audit firms needs to properly select and consider delegating audit components with low audit risks. That is, areas with low audit judgments and subject to less errors. With constant monitoring and instructions, it would ensure the assigned tasks are properly executed.

When selecting a component auditor to assist the primary auditor, the initial auditor needs to understand and be aware of various characteristics. The engagement auditor must understand whether the subcontracted auditor is independent and will comply with all relevant ethical requirements (1). It is important that the subcontracted auditor is independent in regards to the client. This is critical in order to deliver an unbiased and fair audit and also have a certain level of ethical and moral values in a business setting. The professional competence of the component auditor must also be understood. It is critical that the component auditor possesses prior professional experience in conducting audit work that is specific to the work he/she was delegated to perform. The group engagement team must also understand if they will be able to get the information needed for the consolidated process from the component auditor. If communication and proximity between the group engagement team and the component auditor is poor then getting the necessary information from the component auditor may be a huge burden and may result in an inaccurate or incomplete audit. Finally, the group engagement auditor must understand whether the component auditor operates in a regulatory environment that actively oversees auditors.

External auditing firms have few motives to contract outside external auditors or specialists to assist them in their audit engagement. The reasoning could range from lack of specific knowledge of certain accounting/audit areas, to limited staff to complete an engagement. It must be noted that most of the audit firms hired to perform an audit engagement have probably already done their diligence and ensured that they have the sufficient resources to complete the engagement. However, due to the high turnover especially during the busy season, firms could be stranded with insufficient resources. In such case, the engagement or subcontracting of an outside firms could make economic sense. In addition, there could be circumstances when the audit firm might need to engage the work of specialist in auditing or accounting or an expertise in other field. For example: an expertise in estimation of oil and other minerals; the interpretation of contracts, laws, and regulations; or an expert in analysis of complex or unusual tax compliances issues. In the following paragraphs, we would discuss these and some other motives for subcontracting the services of an outside audit firm to assist in the initial audit engagement.

As previously noted, subcontracting an external auditor makes sense in a variety of cases. For instance, in PCAOB, SOX type of engagements of public clients, where the auditor is required to assess the internal control design and operating effectiveness over financial reporting, the auditor could subcontract an outside audit firm to assist in the internal control testing. Such subcontracting would not impair the judgment of the external auditors as they would be able to monitor the process and properly read/access the results. The subcontracting firm could be "feed" with the internal designed controls from the principle auditor. As part of the testing, the subcontracting firm would then create an internal control testing program in which it would spell out the anticipated procedures for testing. This audit program would be reviewed by the initial audit firm and if there is discrepancy between the audit methodologies between the two firms, this would be the time for proper matching. After proper reconciliation takes place, the hired subcontracting audit firm could start the 
internal control testing and provide proper timely reports. These reports could be verified at any time by the initial auditor, as this auditor would require the subcontracting firm to relinquish all audit documents at the end of the audit. This would ensure that proper retention takes place.

In his research, Regan (3) notes some advantages of subcontracting external parties for internal control testing:

- "Additional resource to fulfill a full range of internal auditing responsibilities

- Access to expertise, such as systems auditing and treasury skills, which are unavailable to an internal auditor

- Cost-effectiveness. Some external service providers charge only a percentage of realized cost savings in areas such as accounts payable reviews. The internal auditing function can respond to adapting conditions by temporarily flexing its costs.

- A platform for training in-house auditing staff

- Comparative experience from entities in similar sectors".

We note that the driving trigger (motive) for subcontracting the work to outside parties is to meet short term staffing demands at a reasonable cost without affecting significantly the quality of the work. This transposes as the advantages listed above. That is, we note that the key advantage or trigger for subcontracting consideration is the "cost-effectiveness" listed from the above. We note that a company can always hire more staff to complete an engagement, however the cost to pursue this path might be prohibitively expensive in the short term. This is due the additional training and search costs associated with finding the right candidate for the job who could undertake the project in a very short period of time. In addition, once the project is completed and there is no more need for the candidate, the company need to terminate the employment. On the other hand, if the company is to hire an outside firm to subcontract negotiated services, it could be more cost effective. This is due to the fact that the outside firm is in the business of providing subcontracting work and as such it would have the proper processes, trainings and staff in place to minimize the transition period to minimum. Once the engagement is completed, the firm leaves and it is on standby to further assist when needed.

Further in his paper, Regan (3) notes some of disadvantages of subcontracting and external parties for internal control testing:
- "Inefficiency. The learning curve for external service providers can be steep. An inadequate understanding of the organization may seriously hamper the service provider's effectiveness .

- External service providers may be isolated from the informal networks of the organization, putting them at a disadvantage when navigating the environment.

- External service providers do not offer a systematic internal recruiting ground for future senior managers.

- Confidentiality might be violated if external individuals have access to sensitive information.

- In addition, there are growing regulatory restrictions on and disclosure requirements for the use of internal auditing services provided by external auditing firms. Finally, it is worth drawing attention to the potentially dangerous overreliance on external support: Internal auditing departments must ensure that their organizational status and independence are unaffected by relationships with external service providers. The internal auditing department is responsible for the quality of all audit work, and it cannot let external consultants make executive decisions. A system of check and balances must be in place to help prevent any potential imbalance between the two".

The inefficiency is the key disadvantage to subcontracting. As the company needs to subcontract an outside firm to perform the services, we can have a situation where the firm does not have the proper understanding, training or staff in place to take on the engagement. That is, the firm would not be able to fully meet the needs of the hiring company. In order to avoid such scenario, the firm needs to have the proper processes, trainings and staff in place to minimize the transition period to minimum. These observations have been noted also in the works of Beaverstock (4) and Smith (5).

In general, we note that these advantages and disadvantages are also inherent for the subcontracting of external audit function. That is, the advantages such us cost-effectiveness, comparative experience, access to expertise are all considered advantages of subcontracting the external audit function. The disadvantages are also applicable as with hiring others to perform the audit work, the external firm needs to ensure the others meet the quality standards. 
This would involve additional procedures which otherwise would be unnecessary. However, audit firms need to consider the pros and cons in their specific scenario and determine if subcontracting would benefit their audit.

\section{EXAMPLES OF ROUTING AUDIT PROCEDURES:}

It is important to review some of the routine audit procedures that could be subcontracted. We will review these procedures in the following paragraphs. Please note that these is not all inclusive list but it should be used as a guidance as to the applicable procedures that could be subcontracted to other external auditors.

\section{Cash and $A / R$ confirmations}

The other auditors could assist in keeping real time $\operatorname{logs}$ of the sent/received Cash/A/R confirmation letters. For this purpose, the external audit team will need to make the selections (according to their audit methodology) with the specific requests to the client. Such request would incorporate that the confirmation replies be send to our designated secure mailbox and email. As other auditors receive the confirmations, they would update the confirmation $\log$ and provide periodic status reports on pending cash or $\mathrm{A} / \mathrm{R}$ confirmations. These pending confirmations could be used as a follow up tasks between the external auditor and the client. At completion, the other auditors would email scanned copies and mail the original confirmations for the principle auditor's inclusion in the audit binder. Please note that we could assist the audit team in documentation of subsequent cash receipts for not received $A / R$ confirmations.

\section{Property, Plant and Equipment Additions / Disposal}

The other auditors could assist in testing additions and disposals of Property, Plant and Equipment. For this purpose, the external audit team will need to make the selections (according to their audit methodology) with the specific requests to the client for supporting documentation (such as Approved Purchase Orders, Invoices, Contracts, Subsequent Payments, Disposal agreement). The client needs to be instructed to forward these documents to our designated secure mailbox and email. As other auditors receive the supporting documentation, they would start documenting these additions / disposals. At this point, theu would start performing the necessary procedures to verify the property, plant and equipment additions/disposals. As they receive the supporting documentation, we would provide periodic status reports on pending additions/disposals. These pending items could be used as a follow up tasks between the external auditor and the client. At completion, the other auditors would email scanned copies and mail the original documentation for the principle auditor's inclusion in the audit binder.

\section{Revenue and Expense Substantive Testing of Detail}

The other auditors could assist in testing of detail of Revenue and/or Expenses. For this purpose, the external audit team will need to make the selections (according to their audit methodology) with the specific requests to the client for supporting documentation (such as contracts, A/R invoices, subsequent cash receipts, PO approvals, ect). The client needs to be instructed to forward these documents to their designated secure mailbox and email. Prior to their work, they would need to obtain understanding of these cycles either through performed walkthrough or client provided flowchart or process description. As they receive the supporting documentation, they would start documenting these revenues/expenses. At this point, the other auditors would start performing the necessary procedures to verify the revenue and expense recognition. As they receive the supporting documentation, we would provide periodic status reports on pending tasks. These pending items could be used as a follow up tasks between the external auditor and the client. At completion, they would email scanned copies and mail the original documentation for the principle auditor's inclusion in the audit binder.

\section{Internal Control Testing}

The other auditors could also assist in testing the internal controls of the company. The subcontracting firm could help guide the engagement company's internal control function in determining compliance with SOX rules and regulations. This entails the evaluation of currently established internal control plans to test the design, operating effectiveness and compliance. The approach could be is unique as the firm perform thorough walkthrough of company's internal control environment. The subcontracting firm could also analyze the strengths and weaknesses and as a result, provide an appropriate risk assessment that could truthfully add value to the organization. 
As part of this process, the subcontracting firm would be also able to identify strengths and weaknesses of the internal control environment. As a result of this analysis, the firm could provide recommendations on the establishment of internal controls to mitigate certain financial/fraud risks. For each identified risk, we provide benefit/cost analysis to determine if it would make economic sense for you as a company to establish the proposed controls.

\section{CONCLUSION}

In this paper, we argue that routine audit work could be subcontracted without affecting the quality of the external audit. As key premise to this argument, we note that before such subcontracting could occur, the initial auditors have to be satisfied with subcontracted audit activities and they have to ensure they meet the established standards of audit quality. This could be accomplished by ensuring that the other auditors are independent of the client and qualified enough to handle the assigned tasks. The object of subcontracting external auditors is that the initial auditor could focus on the more technical areas and the subcontractor could focus on routine areas. A reason for subcontracting some portion of the audit to another firm could be due to the audit being large; it could be overwhelming for one team to handle and the time to hire and train new employees could be limited. In such case, it makes sense to hire or subcontract an outside firm to come in and immediately handle the audit.

\section{REFERENCES}

1. AICPA (2012), AU-C Section 600, Special Considerations-Audits of Group Financial Statements (Including the Work of Component Auditors), http://www.aicpa.org/Research/Standards/A uditAttest/DownloadableDocuments/AU-C00600.pdf , Date of Access: 11/25/14

2. AICPA (1972), AU-C Section 543, Part of Audit Performed by Other Independent Auditors, http://www.aicpa.org/Research/Standards/A uditAttest/DownloadableDocuments/AU00543.pdf, Date of Access: 11/25/14

3. Regan, D. (2002), The CPA's Transition to the World of Internal Auditing, The CPA Journal, August, 2002 http://www.nysscpa.org/cpajournal/2002/08 02/nv/nv3.htm, Date of Access: 11/25/14

4. Beaverstock, J. V. (1996). Subcontracting the accountant! Professional labour markets, migration, and organizational networks in the global accountancy industry. Environment and Planning A, 28(2), 303-326.

5. Smith, G. (2007). Outsourcing problem: The right-to-audit clause. Journal of Corporate Accounting \& Finance, 18(5), 19-22 